Address for correspondence: Enrique J. Calderón, CIBER en Epidemiología y Salud Pública, Servicio de Medicina Interna, Hospital Universitario Virgen del Rocío, Avda, Manuel Siurot s/n, 41013 Seville, Spain; e-mail: sandube@cica.es

\section{Delinquent Mortgages, Neglected Swimming Pools, and West Nile Virus, California}

To the Editor: Reisen et al. illustrated the potential relationship between environmental developments, such as those that result from major economic events, and increased risks for infectious diseases (1). The Institute of Medicine landmark report in 1992 on emerging pathogens (2) and the initiative of the Centers for Disease Control and Prevention in 1994 (which helped give rise to the Emerging Infectious Diseases journal) note the role of environmental phenomena in spawning some infectious diseases.

The Reisen et al. report also reflects the utility and limitations of ecologic studies and the legitimacy of simultaneously concluding that study findings are "hypothesis generating" from a scientific perspective yet sufficiently plausible to prompt public health interventions from a practical perspective. The report demonstrates the value of synthesizing multiple streams of surveillance data, observations from field investigations, and contextual awareness of community events to generate hypotheses that bear exploration - in this case, the hypothesis that increases in mosquito habitats resulting from abandonment of swimming pools cause increases in the in- cidence of West Nile virus (WNV) cases. Scientifically, this question was not definitively answered because the study could not directly assess the putative link between disease and exposures to WNV-infected mosquitoes that had bred in abandoned swimming pools in California.

Beyond a priori knowledge that abandoned swimming pools provide opportunities for mosquito breeding (and other hazards, such as drowning), this report raises other critically important questions, such as what action should be taken in response to such findings and how should the findings be communicated to the public? Practically, questions about the link between abandoned swimming pools and illness were sufficiently answered so that public and environmental health officials could respond, as manifested by Kern County's West Nile Virus Strategic Response Plan (3) and related strategies, including the Fight the Bite campaign, which calls for reporting of neglected swimming pools (4). Knowledge regarding the study's limitations about causality should not detract from these efforts, as has been recognized by other sectors, such as the mortgage industry (5).

\section{Richard A. Goodman and James W. Buehler}

Author affiliations: Centers for Disease Control and Prevention, Atlanta, Georgia, USA (R.A. Goodman); and Emory University, Atlanta (J.W. Buehler)

\section{DOI: 10.3201/eid1503.081489}

\section{References}

1. Reisen WK, Takahashi RM, Carroll BD, Quiring R. Delinquent mortgages, neglected swimming pools, and West Nile virus, California. Emerg Infect Dis. 2008;14:1747-9. DOI: 10.3201/ eid1411.080719

2. Institute of Medicine. Emerging infections: microbial threats to health in the United States. Washington: National Academy Press, 1992.

3. Kern County Department of Public Health. Kern County West Nile virus strategic re- sponse plan, May 2008 [cited 2009 Jan 23]. Available from http://www.co.kern. ca.us/health/wnvStrategicResponsePlan. pdf

4. Kern County Department of Public Health. Fight the bite! [cited 2009 Jan 28]. Available from http://www.co.kern.ca.us/ health/GreenPool.pdf

5. Foreclosures loom as possible public health menace. Mortgage News Daily. 2008 Aug 18 [cited 2009 Jan 28]. Available from http://www.mortgagenewsdaily. com/8182008_Foreclosures_West_Nile. asp

Address for correspondence: Richard A. Goodman, Public Health Law Program, Centers for Disease Control and Prevention, 1600 Clifton Rd, Mailstop D30, Atlanta, GA 30333, USA; email: rag4@cdc.gov

In Response: We thank Goodman and Buehler for their comments about our recent article drawing attention to linkages among neglected swimming pools, vector mosquito production, and West Nile virus (WNV) transmission (1). We agree with their comment that our "study could not directly assess the putative link between disease and exposures to WNV-infect-e d mosquitoes that had bred inabandoned swimming pools in California." However, outbreaks of pathogens with complicated transmission cycles rarely afford isolation of any one factor for analysis. Notably, an update of events in Kern County during 2008 may support our previous conclusions. As in 2007, Kern County experienced continued drought conditions in 2008 , and mosquito production was again confined largely to urban sources, including swimming pools. Avian abundance was low, and seroprevalence for $\mathrm{WNV}$ among selected bird species was similar to seroprevalence rates for 2007 (i.e., $7.8 \%$ of 192 house finches, $5.6 \%$ of 90 house sparrows, and $41.2 \%$ of 68 western scrub-jays were seropositive in 2007). However, early in the spring of 2008, unlike in 2007, the Kern Mosquito and Vector 
Control District (MVCD) commenced aerial surveys, reassigned rural field crews to treat swimming pools (and other urban water sources), and immediately conducted ground-based adulticiding when surveillance detected enzootic activity. This aggressive approach resulted in 2,182 swimming pools treated (a $255 \%$ increase over the number treated in 2007), reduced enzootic transmission (i.e., $5 \%$ of 192 dead birds, 17 serum samples from 90 sentinel chickens, and $1 \%$ of 598 mosquito pools positive for WNV), and almost no evidence of human infection (only 1 case reported in October). Intervention by the Kern MVCD, coupled with continuing severe drought conditions that eliminated natural and agricultural-related mosquito produc-

tion sites, effectively eliminated WNV epidemic transmission that had persisted during the 4 previous years (2).

Our study was supported by National Institutes of Health grant R01-AI55607 and the Centers for Disease Control and Prevention.

\section{William K. Reisen, Richard M. Takahashi, Brian D. Carroll, and Rob Quiring}

Author affiliations: University of California, Davis, California, USA (W.K. Reisen, B.D. Carroll); and Kern Mosquito and Vector Control District, Bakersfield, California, USA (R.M. Takahashi, R. Quiring)

\section{References}

1. Goodman RA, Buehler JW. Delinquent mortgages, neglected swimming pools, and West Nile virus, California. Emerg Infect Dis. 2009;15:508.

2. Reisen WK, Carroll BD, Takahashi RM, Fang Y, Garcia S, Martinez VM, et al. Repeated West Nile virus epidemic transmission in Kern County, California, 20042007. J Med Entomol. In press.

Address for correspondence: William K. Reisen, Center for Vector-borne Diseases, University of California, Old Davis Rd, Davis, CA 95616, USA; email: arbo123@pacbell.net

The opinions expressed by authors contributing to this journal do not necessarily reflect the opinions of the Centers for Disease Control and Prevention or the institutions with which the authors are affiliated.

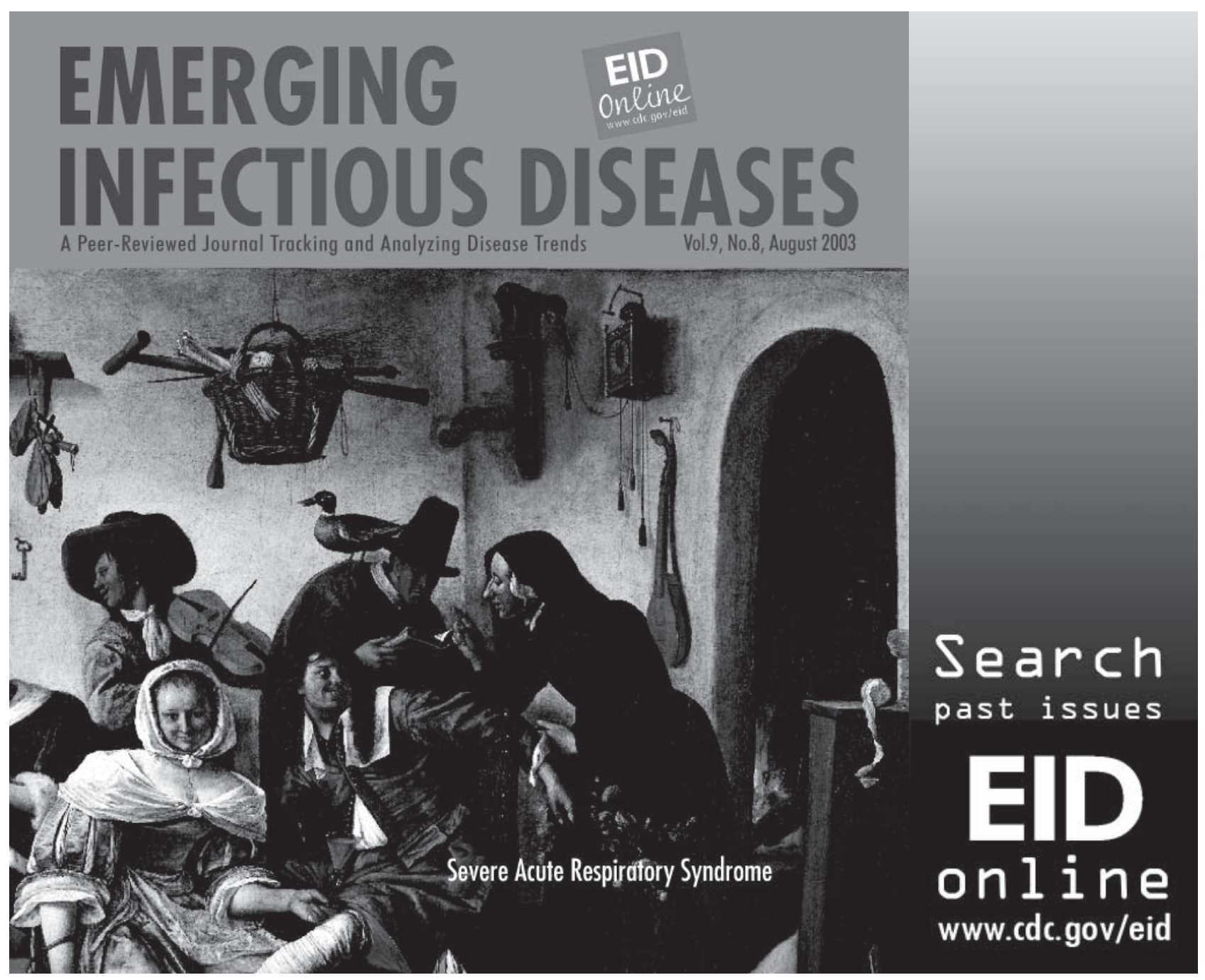

